\title{
ASAP1 mediates the invasive phenotype of human laryngeal squamous cell carcinoma to affect survival prognosis
}

\author{
MINGHUA LI $^{1^{*}}$, LINLI TIAN ${ }^{2 *}$, HONGCHAO YAO $^{1}$, JIANGUANG LU $^{2}$, \\ JINGCHUN GE ${ }^{2}$, YAN GUO ${ }^{2}$, MING LIU ${ }^{1}$ and HUI XIAO ${ }^{2}$ \\ Services of ${ }^{1}$ Head and Neck Surgery, and ${ }^{2}$ Laryngology, Department of Otolaryngology - Head and Neck Surgery, \\ The Second Affiliated Hospital of Harbin Medical University, Harbin, Heilongjiang 150081, P.R. China
}

Received January 25, 2014; Accepted March 24, 2014

DOI: $10.3892 /$ or. 2014.3150

\begin{abstract}
ASAP1 helps regulate cellular structures such as actin cytoskeletal remodeling and focal adhesions that have a pivotal function in tumor progression. Overexpression of ASAP1 has proven to be a malignant indicator for a variety of tumors. To further determine the potential involvement of ASAP1 in laryngeal squamous cell carcinoma (LSCC), we evaluated the expression levels of ASAP1 by quantitative real-time reverse-transcriptase polymerase chain reaction (qRT-PCR) and immunohistochemistry in tissue samples of 64 LSCC patients. We then analyzed and correlated the results with clinicopathological features. Furthermore, we used small interfering RNA (siRNA) to inhibit ASAP1 expression in vitro. The potential function of ASAP1 in invasiveness was evaluated in the Hep-2 LSCC cell line. Kaplan-Meier method was utilized to determine the association of ASAP1 expression with survival of patients. We showed that ASAP1 was upregulated in primary LSCC tumors and was correlated with lymph node metastasis and clinical tumor stage. Similarly, higher levels of ASAP1 were detected in the Hep-2 cell line compared to the 16 human bronchial epithelial (16HBE) cell line. ASAP1 expression was downregulated by lentiviral vector transfection containing siRNA in vitro. The invasive potential of these cells was found to be significantly suppressed, while expression levels of Racl and Cdc42 positively correlated with
\end{abstract}

Correspondence to: Dr Hui Xiao, Service of Laryngology, Department of Otolaryngology - Head and Neck Surgery, The Second Affiliated Hospital of Harbin Medical University, 148 Bao Jian Road, Harbin, Heilongjiang 150081, P.R. China

E-mail: ybbxuz2001@163.com

Dr Ming Liu, Service of Head Neck Surgery, Department of Otolaryngology - Head and Neck Surgery, The Second Affiliated Hospital of Harbin Medical University, 148 Bao Jian Road, Harbin, Heilongjiang 150081, P.R. China

E-mail: liumingorl@qq.com

${ }^{*}$ Contributed equally

Key words: ASAP1, laryngeal squamous cell carcinoma, lentivirus, Rac1, Cdc42, Hep-2 cells the inhibition of ASAP1 expression. In Kaplan-Meier overall survival curves, higher ASAP1 mRNA levels were found to be associated with a shorter progression-free survival trend. Based on these results, ASAP1 appears to contribute to the malignant mechanism of LSCC and may represent a significant prognostic marker for LSCC patients.

\section{Introduction}

ASAP1, also known as AMAP1, DDEF1, DEF1 or centaurin $\beta 4$, is an ADP-ribosylation factor GTP-ase activating protein that induces the hydrolysis of GTP molecules (1-3). ASAP1 contains multiple domains, including BAR, Ankyrin repeat, proline-rich, $\mathrm{SH} 3$ and pleckstrin homology $(\mathrm{PH})$ domains. The $\mathrm{N}$-terminal BAR domain induces membrane tubulation and can function as a protein binding site $(4,5)$, while the Ankyrin and SH3 domains facilitate signaling and interactions by ASAP1 with focal adhesion kinase (FAK), CD2AP, Src and paxillin (6-10). Using its pleckstrin homology domain, ASAP1 also regulates ADP-ribosylation factors (ARFs) which cycle between GDP and GTP states (11).

Organization of the actin cytoskeleton represents a key factor in the formation of membrane ruffles, filopodia and actin-rich protrusions which occur in tumor cells (1,7,12-14). ASAP1 has been shown to have a role in the remodeling of the actin cytoskeleton and in the regulation of intracellular membrane traffic (12). Correspondingly, overexpression of ASAP1 has proved to be a malignant indicator for a variety of tumors such as breast, colorectal, uveal melanomas and prostate (15-18). In addition, ASAP1 has been shown to play an important role in regulating the motility, invasion and metastasis of tumor cells $(19,20)$.

Rac and Cdc42 are small GTP-binding proteins of the Rho family, a subset of the Ras superfamily (21). Racl and Cdc42 have been well-characterized, and similar to the other GTPases, they cycle between a GTP-bound and a GDP-bound form. It is hypothesized that their activity is regulated by a combination of GTPase-activating proteins (GAPs), guanine nucleotide exchange factors and guanine nucleotide dissociation inhibitors (GDIs). As such, these small GTP-binding proteins serve as molecular switches within numerous signal transduction pathways and regulate a diverse set of cellular functions, including control of cell morphology, cell cycle 
progression, cell migration and invasion, cell growth and proliferation, actin dynamics and the transcriptional activation of apoptotic signaling (22-29). However, it is currently unknown whether ASAP1 affects the activation of Rac and Cdc42 in LSCC.

Carcinoma of the larynx is the most common malignant neoplasm of the head and neck and is associated with a high rate of mortality. Moreover, many of these patients are diagnosed with squamous cell carcinomas. Currently, the treatment options for laryngeal carcinoma include radical laryngectomy and conservative chemotherapy or radiotherapy. However, despite advances in these treatment methods, the mortality rate of advanced stage laryngeal cancer remains largely unchanged. Metastasis of primary laryngeal cancers also contributes to the high mortality rates associated with these tumors, and the mechanisms associated with this process remain largely uncharacterized. Thus, mechanistic studies of LSCC metastasis continue to be an important area of research, as well as the identification of more effective biological markers for the diagnosis and prognosis of LSCC.

Currently, it remains unknown whether ASAP1 plays a role in laryngeal carcinoma. Therefore, in the present study, expression of ASAP1 mRNA was detected in laryngeal carcinoma tissues and matched non-tumor tissues using realtime PCR and immunohistochemistry assays. The potential for ASAP1 to regulate the invasive phenotype of Hep-2 cells in vitro was also evaluated using a lentivirus vector system. Finally, the prognostic value associated with ASAP1 mRNA levels was analyzed.

\section{Materials and methods}

Patients and specimens. A retrospective review of 80 adult patients with pathologically confirmed primary LSCC was carried out. Between 2006 and 2007, these patients underwent a partial or total laryngectomy at the Department of Otorhinolaryngology, at the Second Affiliated Hospital of Harbin Medical University. Cancer tissues and corresponding adjacent normal tissues were collected during surgery and were subsequently fixed in formalin and embedded in paraffin (FFPE) according to standard pathology protocols. Patient characteristics for this cohort are listed in Table I. Following treatment, patients underwent follow-up through December 2007, with endpoints classified as: surviving without LSCC, death due to primary recurrent LSCC, death due to other causes and follow-up status unknown. Surviving patients were confirmed by phone or by checking census records. For 64/80 patients, complete clinicopathological data and tumor specimens in a good state of preservation were available. Therefore, these patients were examined in the present study. The study protocol used was in accordance with the institutional guidelines for human research and was approved by the ethics committee.

Lentiviral vector system. A recombinant lentivirus was generated that contained siRNA designed to target the human mRNA sequence of ASAP1 (siRNA-ASAP1) (5'-GACCAG AUCUCUGUCUCGGAGUUCA-3' and 5'-UGAACUCCGA GACAGAGAUCUGGUC-3'), and these were synthesized by Shanghai GeneChem Co., Ltd. (Shanghai, China). A control
Table I. Levels of ASAP1 mRNA and the clinicopathological characteristics of the LSCC patients examined.

\begin{tabular}{|c|c|c|}
\hline $\begin{array}{l}\text { Patient characteristics } \\
\text { (No. of patients) }\end{array}$ & $\begin{array}{c}\text { Levels of } \\
A S A P 1 \text { mRNA } \\
\left(\mathrm{T} / \mathrm{N} \text { ratio }^{\mathrm{a}}\right)\end{array}$ & P-value \\
\hline Gender & & 0.31 \\
\hline Male $(n=42)$ & $4.42 \pm 0.24$ & \\
\hline Female $(n=22)$ & $4.49 \pm 0.29$ & \\
\hline $\mathrm{T}$ classification & & 0.29 \\
\hline $\mathrm{T} 1-2(\mathrm{n}=43)$ & $4.40 \pm 0.26$ & \\
\hline $\mathrm{T} 3-4(\mathrm{n}=21)$ & $4.48 \pm 0.31$ & \\
\hline Lymph node metastasis & & $<0.01$ \\
\hline Negative $(n=39)$ & $4.32 \pm 0.26$ & \\
\hline Positive $(n=25)$ & $4.58 \pm 0.22$ & \\
\hline Differentiation & & 0.32 \\
\hline G1 $(n=47)$ & $4.40 \pm 0.25$ & \\
\hline G2-G3 (n=17) & $4.48 \pm 0.34$ & \\
\hline Clinical stage & & $<0.01$ \\
\hline I-II $(n=36)$ & $4.44 \pm 0.26$ & \\
\hline III-IV (n=28) & $4.59 \pm 0.22$ & \\
\hline Patient age (years) & & 0.88 \\
\hline$<60(\mathrm{n}=24)$ & $4.44 \pm 0.23$ & \\
\hline$\geq 60(n=40)$ & $4.45 \pm 0.26$ & \\
\hline ASAPI mRNA levels & & $<0.01$ \\
\hline Low $(n=32)$ & $4.22 \pm 0.21$ & \\
\hline High $(n=32)$ & $4.63 \pm 0.16$ & \\
\hline
\end{tabular}

${ }^{a} \mathrm{~T} / \mathrm{N}$ ratio, tumor tissue/normal tissue $(\mathrm{T} / \mathrm{N})$ ratio: the fold-change in ASAP1 mRNA levels relative to the human U6 gene in tumor tissues and matched normal tissues according to the $2^{-\Delta \Delta \mathrm{Ct}}$ method. Values indicated are the means \pm standard deviation for each group.

lentivirus was also generated. To monitor transfection efficiency, both lentiviruses included a green fluorescent protein (GFP) cassette. The lentiviruses containing siRNAs targeting ASAP1 and GFP control lentiviruses were titered to $10^{9} \mathrm{U} / \mathrm{ml}$ according to the manufacturer's guidelines (GeneChem).

Cell culture and transfection. The human LSCC cell line, Hep-2, was purchased from the Cell Bank of the Chinese Academy of Science (Shanghai, China). Cells were maintained in Dulbecco's modified Eagle's medium (DMEM; Thermo Fisher Scientific, Waltham, MA, USA) supplemented with $10 \%$ fetal bovine serum (FBS; Shanghai Shenggong Co., Ltd., Shanghai, China) and were maintained at $37^{\circ} \mathrm{C}$ under a humidified atmosphere containing $5 \% \mathrm{CO}_{2}$. Hep-2 cells in the logarithmic phase of growth were seeded in 6-well plates at a concentration of $1 \times 10^{5}$ cells/well for transfection. After $12 \mathrm{~h}$, when cells reached $\sim 40-50 \%$ confluency, $1 \mathrm{ml}$ of complete medium containing lentivirus $\left(10^{8} \mathrm{TU} / \mathrm{ml}\right)$ preparations and polybrene $(8 \mathrm{mg} / \mathrm{ml})$ were added to each well. The cells were incubated at $37^{\circ} \mathrm{C}$ for $12 \mathrm{~h}$. The supernatant from each cell was then removed, and DMEM containing 10\% FBS and 1\% 
penicillin-streptomycin was added. After $24 \mathrm{~h}$, the culture medium was replaced with fresh DMEM. Seventy-two hours post transfection, the mean percentage of GFP-positive cells observed in each well was calculated from three random fields of view (FOV) at x200 magnification using a fluorescence microscope (IX70; Olympus, Tokyo, Japan).

$R N A$ isolation and quantitative real-time PCR. RNA was isolated from well-preserved FFPE tissues using a High Pure RNA Paraffin kit (Roche Applied Science, Mannheim, Germany), according to the manufacturer's instructions. RNA was also isolated from Hep-2 cells using TRIzol reagent (Invitrogen, Carlsbad, CA, USA) according to the manufacturer's instructions. RNA concentrations were determined by absorbance readings at $260 \mathrm{~nm}$, while RNA purity was evaluated according to the $\mathrm{OD}_{260} / \mathrm{OD}_{280}$ absorption ratios obtained. cDNA was reverse transcribed using an All-in-One ${ }^{\mathrm{TM}}$ miRNA qPCR Detection kit (GeneCopoeia, Rockville, MD, USA). The reverse transcription reactions were incubated at $37^{\circ} \mathrm{C}$ for $60 \mathrm{~min}$, then at $70^{\circ} \mathrm{C}$ for $5 \mathrm{~min}$. Real-time PCR was performed using a SYBR-Green Master Mix (Applied Biosystems, Carlsbad, CA, USA) and a 7500 Fast Real-Time PCR system (Applied Biosystems). Reactions were incubated at $95^{\circ} \mathrm{C}$ for $10 \mathrm{~min}$, followed by 45 cycles at $95^{\circ} \mathrm{C}$ for $10 \mathrm{sec}, 60^{\circ} \mathrm{C}$ for $20 \mathrm{sec}$, and $72^{\circ} \mathrm{C}$ for $15 \mathrm{sec}$. Expression data were normalized to human U6 gene expression data obtained in parallel as an external reference using the $2^{-\Delta \Delta \mathrm{Ct}}$ method. The forward and reverse primers used for detection of ASAP1 included: 5'-TG TAGTCTTACTTGAAGAGGATGGACC-3' and 5'-CCCTC CCAGCCCACTACCT-3', respectively, and were synthesized by GeneCore BioTechnologies Co., Ltd. (Shanghai, China). Each reaction was performed in triplicate.

Invasion assay. Seventy-two hours post-transduction, cells $\left(2 \times 10^{4}\right)$ were resuspended in $200 \mu 1$ serum-free medium and were plated in the upper chambers of Boyden chambers (24-well, 8-mm pores) coated with Matrigel (Becton-Dickinson Labware, NJ, USA). The lower chambers contained $1 \mathrm{ml}$ medium containing $10 \%$ FBS as a chemoattractant. Untreated Hep-2 cells were also plated as controls. After $24 \mathrm{~h}$, cells were mechanically removed from the upper side of the filters, while cells that had migrated to the lower side of the filters were fixed in $4 \%$ paraformaldehyde and stained with hematoxylin and eosin (H\&E). The number of cells present in three $\mathrm{x} 200$ microscopic fields for each well were averaged and reported. Five independent experiments were performed.

Western blotting. Cells from the siRNA lentivirus group, the GFP control lentivirus group, and untreated Hep-2 cells were harvested $72 \mathrm{~h}$ post-transfection and incubated in cell lysis buffer for $30 \mathrm{~min}$ on ice. Cell lysates were separated using $10 \%$ sodium dodecyl sulphate-polyacrylamide gel electrophoresis (SDS-PAGE) and then were transferred to polyvinylidene fluoride (PVDF) membranes. After incubating the membranes in 5\% skim milk in Tris-buffered saline containing $0.05 \%$ Tween-20 (TBST), the membranes were incubated with primary antibodies overnight at $4^{\circ} \mathrm{C}$. The primary antibodies used included rabbit anti-human ASAP1 (1:500; Abcam, Cambridge, MA, USA), rabbit anti-human rac1 (1:100; Abnova, Taipei, Taiwan), and rabbit anti-human Cdc42 (1:200;

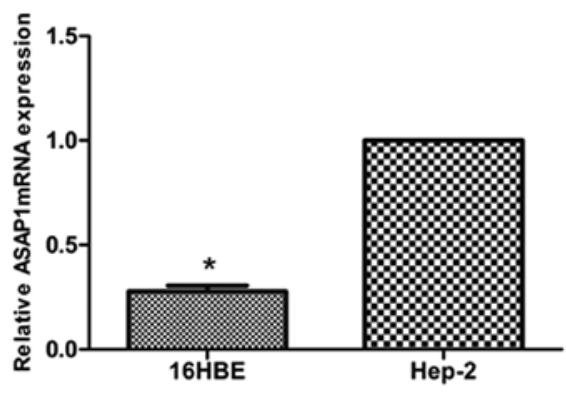

Figure 1. Expression of ASAP1 mRNA in Hep-2 cells vs. 16HBE cells. Levels of ASAP1 mRNA were 3.6-fold higher in the Hep-2 cells compared to the $16 \mathrm{HBE}$ cells as detected by real-time RT-PCR. ${ }^{*} \mathrm{P}<0.05$.

Bioss, Beijing, China). The membranes were then washed with TBTS and incubated with species-appropriate horseradish peroxidase (HRP)-conjugated secondary antibodies for $1 \mathrm{~h}$ at $37^{\circ} \mathrm{C}$. $\beta$-actin served as a loading control, and bands were quantified using ImageJ software (National Institutes of Health, Bethesda, MD, USA). Three independent experiments were performed.

Immunohistochemistry. FFPE specimens were sequentially sectioned ( $4 \mu \mathrm{m}$ each). After deparaffinization and rehydration, sections were treated with $0.3 \% \mathrm{H}_{2} \mathrm{O}_{2}$, and then were incubated with $10 \%$ normal goat serum. Antigen retrieval was performed using EDTA (pH 8.0) at $100^{\circ} \mathrm{C}$ for $20 \mathrm{~min}$. Sections were then washed, and incubated with the primary antibodies at $4^{\circ} \mathrm{C}$ overnight. Sections were subsequently incubated at $37^{\circ} \mathrm{C}$ for $45 \mathrm{~min}$ before being washed and incubated with secondary antibodies at room temperature. After $1 \mathrm{~h}$, sections were washed and incubated with diaminobenzidine tetrachloride for $10 \mathrm{~min}$. Sections were also counterstained with haematoxylin. Negative controls were prepared in parallel and were incubated with PBS instead of the primary antibodies.

ASAP1 scoring. ASAP1 immunoreactivity was evaluated in blinded analyses performed by two pathologists. Staining intensity was graded from 1 to 4 , and these scores indicated an absence of staining (receiving a score of 1) up to strong staining of ASAP1 (receiving a score of 4). Mean score values for each sample were reported.

Statistical analysis. The SPSS statistical software package was used for all calculations. An independent t-test was used to analyze differences in ASAP1 mRNA levels, ASAP1 protein scoring, and the invasive phenotype between groups. Overall survival (OS) was defined as the time period from the date of surgery to the date of death due to LSCC or other causes, or to the end of the study (2011-12-31). The log-rank test was used to evaluate the association of risk factors with time-to-event endpoints. OS curves were also calculated using the KaplanMeier method. A P-value $<0.05$ was considered to indicate a statistically significant result.

\section{Results}

ASAP1 is overexpressed in human LSCC both in vivo and in vitro. Real-time PCR was used to determine the expression 
A

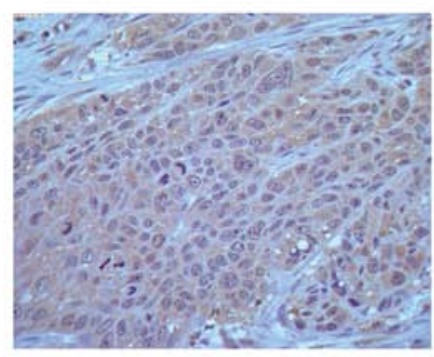

B

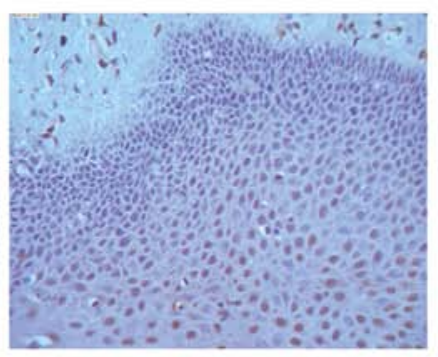

C

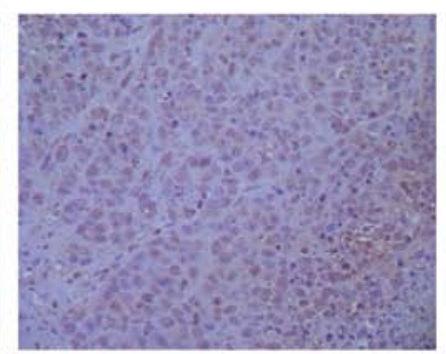

D

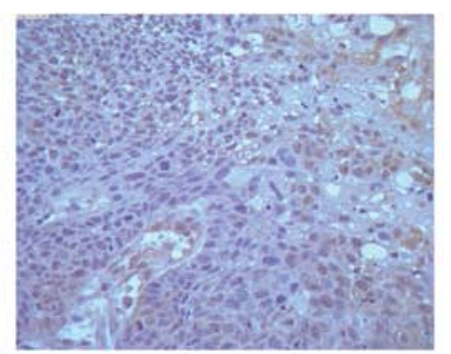

Figure 2. Immunohistochemical staining of ASAP1. Grading of ASAP1 staining was performed. Tissues A-D received scores of 1-4, respectively, and represent (A) weak staining, (B) clear but not strong staining, (C) strong staining (D) and strongest staining observed for ASAP1. Original magnification, x200.

A

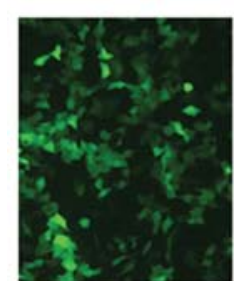

a

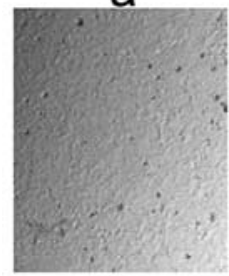

C

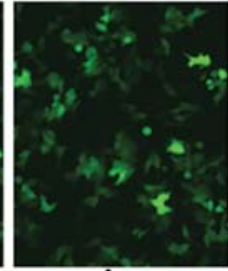

b

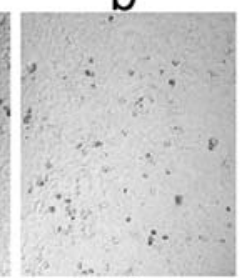

d
B

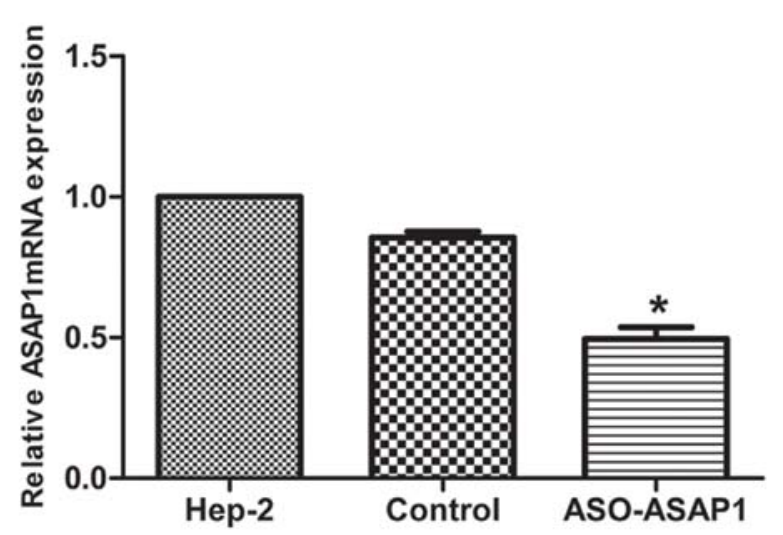

Figure 3. Relative expression of ASAP1 mRNA in Hep-2 cells transfected with the lentiviruses. (A) Fluorescence microscopic images of (a) siRNA-ASAP1treated Hep-2 cells and (b) GFP control cells. Light microscopic images of (c) siRNA-ASAP1-treated Hep-2 cells and (d) GFP control cells. (B) Hep-2 cells transfected with siRNA-ASAP1 lentivirus exhibited a significantly lower level of ASAP1 mRNA compared with Hep-2 cells transfected with a GFP control lentivirus or untreated Hep-2 cells in the real-time RT-PCR assays. ${ }^{*} \mathrm{P}<0.05$.

status of ASAP1 mRNA for both FFPE LSCC tissue samples and matched normal tissue samples obtained from 64 patients diagnosed with LSCC. For the LSCC samples, the mean mRNA level for ASAP1 was 4.45-fold higher than that of the corresponding matched samples (range, 3.76-4.97; median, 4.41) $(\mathrm{P}<0.05)$. Based on these data, the LSCC patients were divided into a low expression group (ASAP1 mRNA level 54.41) and a high expression group (ASAP1 mRNA >4.47). A similar observation was made in vitro, where the Hep-2 cells exhibited higher levels of ASAP1 mRNA than the $16 \mathrm{HBE}$ cells (Fig. 1).

Consistent with the mRNA levels detected for ASAP1, immunohistochemistry assays detected stronger expression of ASAP1 in tissue sections from the high expression group compared to tissue sections from the low expression group. Moreover, the mean ASAP1 score for the high expression group $(2.63 \pm 0.87)$ was significantly higher than that of the low expression group $(2.19 \pm 0.82)(\mathrm{P}<0.05)$. ASAP1 expression was also detected in a subset of the normal tissues stained, although the staining intensity was much weaker compared to that observed for the cancer tissues, particularly in the cytoplasm (Fig. 2).
Levels of ASAP1 mRNA and clinicopathological factors. We analyzed the relationships between levels of ASAP1 mRNA in the LSCC tumors and the clinical data from these patients (Table I). There were no obvious differences in the mRNA levels associated with gender, tumor grade and patient age. However, significantly higher levels of ASAP1 mRNA present in LSCC tissues were associated with lymph node metastasis and clinical tumor stage. For example, patients with higher ASAP1 mRNA levels tended to have an advanced clinical stage of LSCC or lymph node metastasis. These results suggest that upregulated expression of ASAP1 mRNA correlates with the progression of LSCC and an invasive phenotype.

Targeting of ASAP1 mRNA in the Hep-2 cells. In order to investigate the biological function of ASAP1 in LSCC, recombinant lentiviruses containing specific siRNA designed to target the human mRNA sequence of ASAP1, as well as a GFP cassette, were created. Seventy-two hours after Hep-2 cells were transfected with siRNA-ASAP1 and GFP control lentiviruses, $>80 \%$ of the Hep- 2 cells were observed to express GFP, indicating the efficiency and stability of the transductions performed (Fig. 3A). These cells were then subjected to 
A

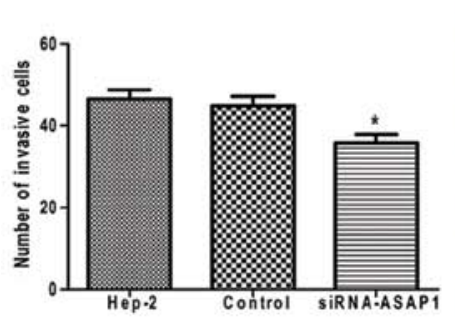

B

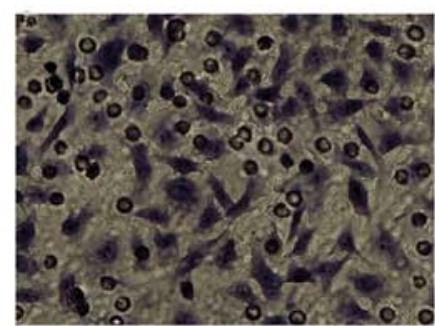

C

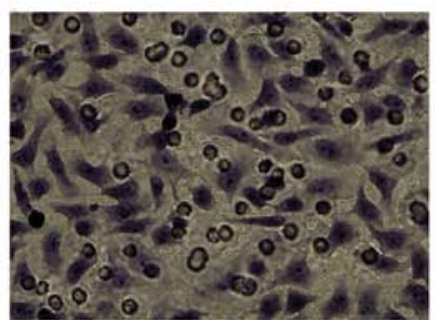

D

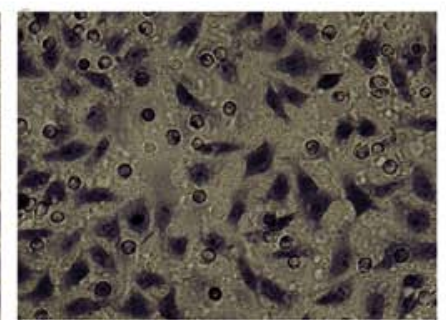

Figure 4. Invasive phenotype of the lentivirus-transfected cells. (A) The average number of Hep-2 cells in each group that migrated to the lower chambers of Transwell plates in FOV ( $\mathrm{P}<0.05$ ). (B) Representative image of migrating cells in the untreated group $72 \mathrm{~h}$ after transfection. (C) Representative image of migrating cells in the GFP group $72 \mathrm{~h}$ after transfection. (D) Representative image of migrating cells in the siRNA-ASAP1 group $72 \mathrm{~h}$ after transfection.

A

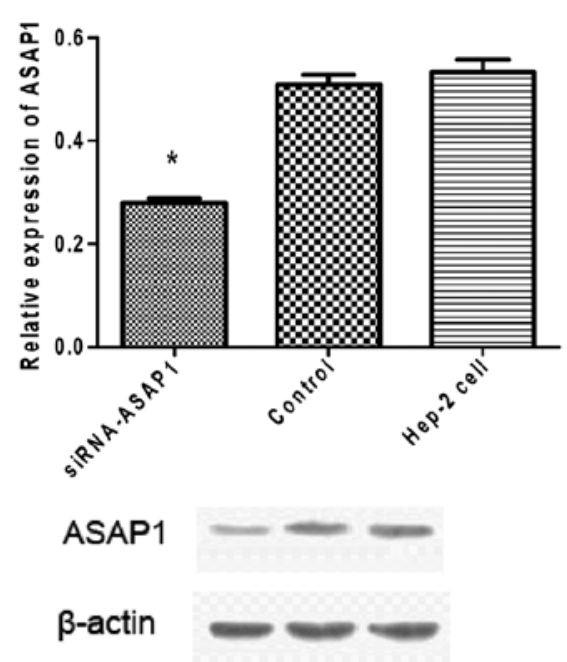

B

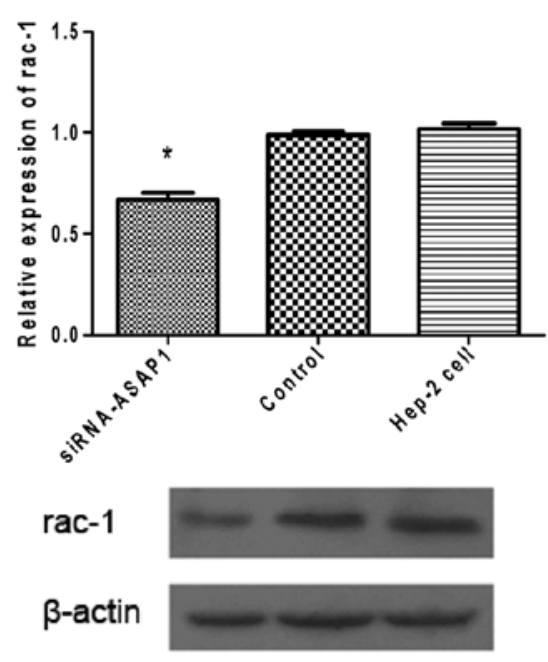

C

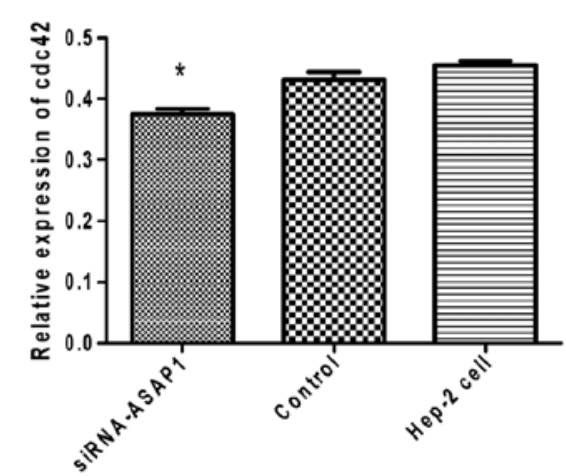

$\operatorname{cdc} 42$

$\beta$-actin

Figure 5. ASAP1 expression positively correlates with Rac1 and Cdc42 expression. (A) Downregulation of ASAP1 mRNA in the Hep-2 cells transfected with siRNA-ASAP1 lentivirus resulted in lower levels of ASAP1 expression compared to cells transfected with the GFP control lentivirus or the untransfected cells $(\mathrm{P}<0.05)$. In these same samples, lower levels of $(\mathrm{B}) \mathrm{Rac1}$ and $(\mathrm{C}) \mathrm{Cdc} 42$ expression were detected in the siRNA-ASAP1 samples but not in the GFP control cells and untreated Hep-2 cells. Detection of $\beta$-actin was used as a loading control. ${ }^{*} \mathrm{P}<0.05$.

quantitative real-time PCR. Levels of ASAP1 mRNA were found to be considerably lower in the cells transfected with the siRNA-ASAP1 lentivirus compared to the GFP control and untreated cells, thereby validating the use of this lentiviral vector system for studies of ASAP1 $(\mathrm{P}<0.05)$ (Fig. 3B).

Downregulation of ASAP1 suppresses the invasion of Hep-2 cells in vitro. To investigate whether ASAP1 contributes to the invasive phenotype of Hep-2 cells, invasion assays were performed using 24-well Boyden chambers coated with Matrigel. As shown in Fig. 4, the number of siRNA-ASAP1treated Hep-2 cells exhibiting an invasive phenotype $72 \mathrm{~h}$ after transfection $(35.8 \pm 4.49)$ was less than that observed for GFP control-treated Hep-2 cells $(44.8 \pm 5.07)$ and untreated Hep-2 cells $(46.4 \pm 5.32)(\mathrm{P}<0.05)$. These data strongly suggest that downregulation of ASAP1 may mediate a reduction in the invasiveness of laryngeal carcinoma cells.

ASAP1 expression positively correlates with Racl and Cdc42 expression. Western blotting was used to measure expression levels of ASAP1, Rac1 and Cdc42 in the Hep-2 cells trans- fected with siRNA-ASAP1 and GFP control lentiviruses. When Hep-2 cells were transfected with the siRNA-ASAP1 lentivirus, lower levels of ASAP1 were detected compared to cells transfected with the GFP control lentivirus or untransfected cells $(\mathrm{P}<0.05)$ (Fig. 5). In these cells, lower levels of Rac1 and Cdc42 expression were also detected. In contrast, cells transfected with the GFP control lentivirus did not show any significant changes in the expression of these three proteins compared to the untransfected Hep-2 cells $(\mathrm{P}>0.05)$.

Prognostic significance of ASAP1 mRNA levels. Of the 64 patients examined, 26 died during the follow-up period. Depending on the levels of ASAP1 that were detected, the 3-year survival probability was 65.6 and $81.3 \%$ for cases with high vs. low levels of ASAP1 mRNA, respectively. The 5-year survival probability for the same groups was 43.8 and $75.0 \%$, respectively $(\mathrm{P}<0.05)$ (Fig. 6). Taken together, these results suggest that patients with LSCC tumors that express high levels of ASAP1 have a poor prognosis and will experience a shorter survival period compared with patients presenting with LSCC tumors that express low levels of ASAP1. 


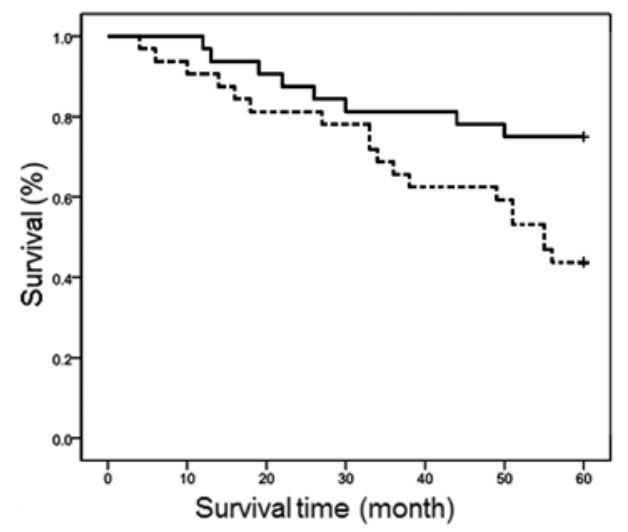

Figure 6. Kaplan-Meier overall survival (OS) curves. A significantly shorter 5-year OS rate was observed for patients with LSCC expressing high levels of ASAP1 (43.8\%; $n=32$; lower curve) compared with the OS of LSCC patients with low levels of ASAP1 $(75 \% ; n=32$; upper curve) $(\mathrm{P}=0.018)$.

\section{Discussion}

Despite advances achieved in the diagnosis and treatment of LSCC in recent years, the long-term survival rate for LSCC, and especially the survival rate for advanced stages of LSCC, have not significantly improved. In addition, metastasis of LSCC still represents a significant challenge, and contributes to the mortality rates reported for LSCC patients each year. While the expression of various genes has been correlated with the development of metastatic LSCC, and some of these have the potential to serve as markers of tumor progression in the clinic $(30,31)$, the mechanistic details for LSCC remain to be determined.

Previously, Miyata et al (32) identified a region in the 5'-UTR of AMAP1 that exhibits a significant internal ribosome entry site (IRES) activity in differentiated U937 cells. Moreover, this activity appears to be necessary for enhanced AMAP1 expression in this cell line. However, this IRES-dependent mechanism for AMAP1 expression may not be conserved in all tumor cells. Currently, the role of ASAP1 in LSCC remains largely uncharacterized. In colorectal tumors, ASAP1 expression is strongly upregulated (16), and Lin et al (18) reported that levels of ASAP1 were elevated in $80 \%$ of primary prostate cancer samples. The results of the present study are consistent with these results, and further demonstrated that both mRNA and protein levels of ASAP1 were upregulated in LSCC tissues compared to paired normal tissues. A similar observation was made in vitro for the Hep- 2 and $16 \mathrm{HBE}$ cell lines. Based on these findings, it is hypothesized that high levels of ASAP1 expression contribute to LSCC.

Cell dissemination is a complex cell motility phenomenon that requires the coordination of protrusion, chemotaxis, invasion and contractile activities of cancer cells in order to achieve directed cell migration. Roles for ASAP1 in actin cytoskeleton remodeling and local adhesion have previously been demonstrated $(6,12)$. More recently, ASAP1 has been implicated in mediating the invasive phenotypes of tumor cells $(33,34)$. In the present study, Boyden chamber assays were used to characterize the role of ASAP1 in relation to the invasive phenotype of LSCC in vitro, and overexpression of ASAP1 was found to promote the invasive activity of
Hep-2 cells. Similarly, ASAP1 has been shown to mediate the invasion and metastasis of breast cancer cells via the EGFRGEP100-Arf6-AMAP1 signaling pathway, or in cooperation with CIN85 or Rab5c (35-37). Overexpression of ASAP1 has also been associated with increased invasion and metastatic potential of high-grade uveal melanomas (17). Therefore, the findings of the present study are consistent with the results obtained using other tumor models, and further support a role for ASAP1 in tumor invasion.

Directed cell migration involves modulation of the actin cytoskeleton by Rho GTPases. In fibroblasts, Rac proteins regulate the formation of lamellipodia and membrane ruffles, as well as the subsequent formation of stress fibers $(38,39)$. In contrast, $\mathrm{Cdc} 42$ plays a key role in the formation of filopodia at the cell periphery, and this is followed by the formation of lamellipodia and membrane ruffles (40). When ASAP1 was downregulated in Hep-2 cells using an siRNA targeting ASAP1 lentivirus, cell invasion was inhibited. Furthermore, reduced ASAP1 expression also positively correlated with the protein levels detected for Rac1 and Cdc42. Taken together, these results suggest that decreased expression of Rac1 and Cdc42 may also contribute to the invasive phenotype of Hep-2 cells.

To determine whether ASAP1 expression levels affect the prognosis of laryngeal cancer patients, the median level of ASAP1 mRNA that was identified in 64 LSCC patients was used to establish a high ASAP1 expression level group and a low ASAP1 expression level group. The former was associated with a higher mortality rate, as well as a higher rate of relapse. To the best of our knowledge, this is the first study to investigate the effect of ASAP1 expression on the recurrence and mortality of LSCC. Given the small sample size of this study, additional studies are needed to validate the present results. However, the results of the present study do highlight the potential for ASAP1 to be considered as a risk factor for human laryngeal carcinoma.

Based on the results obtained, ASAP1 appears to have an oncogenic role in the metastasis of laryngeal tumors. Therefore, it is hypothesized that ASAP1 mRNA and ASAP1 represent therapeutic targets and prognostic biomarkers that should be considered and evaluated for LSCC.

\section{Acknowledgements}

We thank the Department of Otorhinolaryngology at the Second Affiliated Hospital of Harbin Medical University for providing human laryngeal tissue samples. The present study was supported by grants from the National Science Foundation of China (81241085); the Key Project of Natural Science Foundation of Heilongjiang Province (ZD201215/H1302); the Research Fund for the Doctoral Program of Higher Education of China (20102307110007) and the Postdoctoral Science Foundation of Heilongjiang Province (LBH-Z11087).

\section{References}

1. Inoue $\mathrm{H}$ and Randazzo PA: Arf GAPs and their interacting proteins. Traffic 8: 1465-1475, 2007.

2. Buffart TE, Coffa J, Hermsen MA, et al: DNA copy number changes at 8q11-24 in metastasized colorectal cancer. Cell Oncol 27: 57-65, 2005.

3. Martin RK and Jackson TR: Centaurin $\beta 4$ in cancer. Biochem Soc Trans 33: 1282-1284, 2005. 
4. Inoue H, Ha VL, Prekeris R and Randazzo PA: Arf GTPaseactivating protein ASAP1 interacts with Rab11 effector FIP3 and regulates pericentrosomal localization of transferrin receptorpositive recycling endosome. Mol Biol Cell 19: 4224-4237, 2008

5. Jian X, Brown P, Schuck P, et al: Autoinhibition of Arf GTPaseactivating protein activity by the BAR domain in ASAP1. J Biol Chem 284: 1652-1663, 2009.

6. Liu Y, Loijens JC, Martin KH, Karginov AV and Parsons JT: The association of ASAP1, an ADP ribosylation factor-GTPase activating protein, with focal adhesion kinase contributes to the process of focal adhesion assembly. Mol Biol Cell 13: 2147-2156, 2002.

7. Liu Y, Yerushalmi GM, Grigera PR and Parsons JT: Mislocalization or reduced expression of Arf GTPase-activating protein ASAP1 inhibits cell spreading and migration by influencing Arf1 GTPase cycling. J Biol Chem 280: 8884-8892, 2005.

8. Brown MT, Andrade J, Radhakrishna H, et al: ASAP1, a phospholipid-dependent arf GTPase-activating protein that associates with and is phosphorylated by Src. Mol Cell Biol 18: 7038-7051, 1998.

9. Bharti S, Inoue $\mathrm{H}$, Bharti $\mathrm{K}$, et al: Src-dependent phosphorylation of ASAP1 regulates podosomes. Mol Cell Biol 27: 8271-8283, 2007.

10. King FJ, Hu E, Harris DF, Sarraf P, Spiegelman BM and Roberts TM: DEF-1, a novel Src SH3 binding protein that promotes adipogenesis in fibroblastic cell lines. Mol Cell Biol 19: 2330-2337, 1999

11. Kam JL, Miura K, Jackson TR, et al: Phosphoinositide-dependent activation of the ADP-ribosylation factor GTase-activating protein ASAP1. Evidence for the pleckstrin homology domain functioning as an allosteric site. J Biol Chem 275: 9653-9663, 2000.

12. Randazzo PA, Andrade J, Miura K, et al: The Arf GTPaseactivating protein ASAP1 regulates the actin cytoskeleton. Proc Natl Acad Sci USA 97: 4011-4016, 2000.

13. Nie Z and Randazzo PA: Arf GAPs and membrane traffic. J Cell Sci 119: 1203-1211, 2006.

14. Donaldson JG and Jackson CL: ARF family G protein and their regulators: roles in membrane transport, development and disease. Nat Rev Mol Cell Biol 12: 362-375, 2011.

15. Onodera Y, Hashimoto S, Hashimoto A, et al: Expression of AMAP1, an ArfGAP, provides novel targets to inhibit breast cancer invasive activities. EMBO J 24: 963-973, 2005.

16. Muller T, Stein U and Poletti A: ASAP1 promotes tumor cell motility and invasiveness, stimulates metastasis formation in vivo, and correlates with poor survival in colorectal cancer patients. Oncogene 29: 2393-2403, 2010.

17. Ehlers JP, Worley L, Onken MD and Harbour JW: DDEF1 is located in an amplified region of chromosome $8 \mathrm{q}$ and is overexpressed in uveal melanoma. Clin Cancer Res 11: 3609-3613, 2005.

18. Lin D, Watahiki A, Bayani J, et al: ASAP1, a gene at $8 \mathrm{q} 24$, is associated with prostate cancer metastasis. Cancer Res 68 4352-4359, 2008.

19. Randazzo PA, Inoue $\mathrm{H}$ and Bharti S: Arf GAPs as regulators of the actin cytoskeleton. Biol Cell 99: 583-600, 2007.

20. Furman C, Short SM, Subramanian RR, Zetter BR and Roberts TM: DEF-1/ASAP1 is a GTPase-activating protein (GAP) for ARF1 that enhances cell motility through a GAP-dependent mechanism. J Biol Chem 277: 7962-7969, 2002.

21. Bar-Sagi D and Hall A: Ras and Rho GTPases: a family reunion. Cell 103: 227-238, 2000.

22. Wagner AC and Williams JA: Low molecular weight GTP-binding proteins: molecular switches regulating diverse cellular functions. Am J Physiol 266: G1-G14, 1994.
23. Waschke J, Burger S, Curry FR, Drenckhahn D and Adamson RH: Activation of Rac-1 and Cdc42 stabilizes the microvascular endothelial barrier. Histochem Cell Biol 125: 397-406, 2006.

24. Lamarche N, Tapon N, Stowers L, et al: Rac and Cdc42 induce actin polymerization and G1 cell cycle progression independently of p65PAK and the JNK/SAPK MAP kinase cascade. Cell 87: 519-529, 1996.

25. Yang FC, Atkinson SJ, Gu Y, et al: Rac and Cdc42 GTPases control hematopoietic stem cell shape, adhesion, migration, and mobilization. Proc Natl Acad Sci USA 98: 5614-5618, 2001.

26. Huang M, Satchell L, Duhadaway JB, Prendergast GC and LauryKleintop LD: RhoB links PDGF signaling to cell migration by coordinating activation and localization of Cdc42 and Rac. J Cell Biochem 112: 1572-1584, 2011.

27. Kaibuchi K, Kuroda S and Amano M: Regulation of the cytoskeleton and cell adhesion by the Rho family GTPases in mammalian cells. Annu Rev Biochem 68: 459-486, 1999.

28. Engers R, Springer E, Michiels F, Collard JG and Gabbert HE: Rac affects invasion of human renal cell carcinomas by up-regulating tissue inhibitor of metalloproteinases (TIMP)-1 and TIMP-2 expression. J Biol Chem 276: 41889-41897, 2001.

29. Filipenko NR, Attwell S, Roskelley C and Dedhar S: Integrinlinked kinase activity regulates Rac- and Cdc42-mediated actin cytoskeleton reorganization via $\alpha$-PIX. Oncogene 24: 5837-5849, 2005.

30. Fidler IJ: The pathogenesis of cancer metastasis: the 'seed and soil' hypothesis revisited. Nat Rev Cancer 3: 453-458, 2003.

31. Foley R, Hollywood D and Lawler M: Molecular pathology of prostate cancer: the key to identifying new biomarkers of disease. Endocr Relat Cancer 11: 477-488, 2004.

32. Miyata M, Raven JF, Baltzis D, Koromilas AE and Sabe H: IRES-mediated translational control of AMAP1 expression during differentiation of monocyte U937 cells. Cell Cycle 7: 3273-3281, 2008.

33. Jackson TR, Brown FD, Nie Z, et al: ACAPs are arf6 GTPaseactivating proteins that function in the cell periphery. J Cell Biol 151: 627-638, 2000.

34. Kondo A, Hashimoto S, Yano H, Nagayama K, Mazaki Y and Sabe H: A new paxillin-binding protein, PAG3/Pap $\alpha /$ KIAA0400, bearing an ADP-ribosylation factor GTPase-activating protein activity, is involved in paxillin recruitment to focal adhesions and cell migration. Mol Biol Cell 11: 1315-1327, 2000.

35. Sabe H, Hashimoto S, Morishige M, et al: The EGFR-GEP100Arf6-AMAP1 signaling pathway specific to breast cancer invasion and metastasis. Traffic 10: 982-993, 2009.

36. Nam JM, Onodera Y, Mazaki Y, Miyoshi H, Hashimoto S and Sabe H: CIN85, a Cbl-interacting protein, is a component of AMAP1-mediated breast cancer invasion machinery. EMBO J 26: 647-656, 2007.

37. Onodera Y, Nam JM, Hashimoto A, et al: Rab5c promotes AMAP1-PRKD2 complex formation to enhance beta1 integrin recycling in EGF-induced cancer invasion. J Cell Biol 197: 983-996, 2012.

38. Ridley AJ, Paterson HF, Johnston CL, Diekmann D and Hall A: The small GTP-binding protein rac regulates growth factorinduced membrane ruffling. Cell 70: 401-410, 1992.

39. Chianale F, Cutrupi S, Rainero E, et al: Diacylglycerol kinasealpha mediates hepatocyte growth factor-induced epithelial cell scatter by regulating Rac activation and membrane ruffling. Mol Biol Cell 18: 4859-4871, 2007.

40. Nobes CD and Hall A: Rho, rac, and cdc42 GTPases regulate the assembly of multimolecular focal complexes associated with actin stress fibers, lamellipodia, and filopodia. Cell 81: 53-62, 1995. 